\title{
Study on Cross-Administration Innovation System of the Yangtze River Delta
}

\author{
Dae Shik Lee (Corresponding author) \\ Professor, Department of Economics \\ Pusan National University \\ E-mail: daslee@pnu.edu \\ Hongda Liu \\ Economics Department of Business School \\ Busan National University \\ E-mail: Chinaren820112@hotmail.com \\ Yilong Pan \\ Management Department of Business School \\ Changwon National University \\ E-mail: Pyl823@hotmail.com
}

\begin{abstract}
Since the decentralization of China, regional governments have got more power on how to allocate their investment and set the performance criteria for economic sectors. Strengthened by the regional specific culture, geography and language, administration-based regional innovation system developed quite rapidly in China with great diversity. But with the development of the regional economy, when the traditional administrative division overemphasizes this local benefit to prevent innovation essential factors from flowing and restrict innovation efficiency, the innovation system must surmount the administrative division to carry on innovation in an appropriate region. According to analysis of the yearbooks of Jiang and Zhe provinces and Shanghai, we discovered that the Yangtze River Delta CARIS is a developing model that is a core impetus and supplementary coexisting model and meanwhile a circle proliferation model. Through the research of innovation system in the Yangtze River Delta, the establishment of CARIS is hardly needed in China for the reason of special administrative divisions. Meanwhile, some suggestions are given about how to promote the cross-administration innovation system.
\end{abstract}

Keywords: Cross-administration, Regional innovation system, The Yangtze River Delta, Systematical interaction

\section{Introduction of CARIS}

\subsection{Origin of CARIS}

Since the decentralization of China, regional governments have got more power on how to allocate their investment and set the performance criteria for economic sectors. Strengthened by the regional specific culture, geography and language, administration-based regional innovation system developed quite rapidly in China with great diversity. But with the development of the regional economy, when the traditional administrative division overemphasizes this local benefit to prevent innovation essential factors from flowing and restrict innovation efficiency, the innovation system must surmount the administrative division to carry on innovation in an appropriate region. Through the research of innovation system in the Yangtze River Delta, the establishment of CARIS is hardly needed in China for the reason of special administrative divisions.

\subsection{Development of model}

The framework of CARIS includes innovation power from the enterprises as the main body, the government function as suitable guidance role, the equal network relations among the innovation main bodies, close cooperation among Enterprises, Campuses and Research Institutes and good innovation environment based on the rich social capital and so on. According to system theory of the urban system and space research, Haggett proposed evolutionary process among areas belonging to the CARIS may be analyzed from 6 factors such as: "the interactions", "the network", "the node", "the rank system", "the surface" and "the proliferation". Each region becomes the node of the CARIS, and interacts in the network system forming process. The layers with different ranks are possibly formed according to the local development level, and the prominent nodes also possibly become the central shaft of the network diffusing to other nodes. Profiting from the research summary of Chinese urban regional structure (Yan Xiaopei 1994) and analysis of the urban primacy ratio, the urban system may be divided into types as the double pole type, balanced type and the polar 
nucleus type and so on. For this concept, we may generalize the development models of the CARIS as follow types: Core impetus type, equal network supplementary type, core impetus type and supplementary coexisting type as well as layer and network type and so on. Certainly, with the characteristic about different regions and the different development phases, the CARIS is usually mixed up by many types of development models.

\section{European Union's, Korean and Japanese instance analysis}

\subsection{European Union: Strengthen International scientific and technological cooperation}

The European Union treaty subscribed in 1993 proposed that one of four big essential targets of European Union was to well develop and make use of the innovation, the research and technical achievements with the latent commercial value. In 1994, European Union has formulated the fourth framework program for research and the technical development, and invested 13.1 billion Euro in 20 plans for technical cooperation campaign which includes 4 fields such as the R\&D and demonstrating, the international technical cooperation, promotion of the research and the researchers training. Large quantities of European Enterprises and the research organizations were involved in this plan, thus the supranational large-scale science plan including a variety of participations like countries' governments, the scientific and technical departments and the business communities has formed. In 1997, European Union Committee also proposed the fifth $R \& D$ framework program emphatically engaging in research for the life and the ecology science, the information technology as well as the sustainable development technology. In 2001 the sixth framework program was promoted, and the goal is to serve the construction of the European research area. Meanwhile it proposed seven big projects giving priority to develop, like the biological technology and so on.

(1) Guarantee the innovation policy identical

(2) Establish one management framework in favor of innovation

(3) Encourage establishment and development for innovation enterprises

(4) Improve essential agency in innovation system

(5) Japan: Establish region information cluster taking city as central

Japanese Government announced "the science and technology fundamental law" in 1995, and this became the basic law of science and technology policy in Japanese. Japanese Government has successively formulated two five-year plans "the science and technology basic plan" (1996-2000 and 2001-2005). Aiming at the regional science and technology these mainly facilitates to cause the region "the information cluster" and the smoothly implement regional science and technology policy.

2.1.1 The policy taking establishment of the information cluster and the industrial cluster as goal

The information cluster is technology innovation system that a set of enterprises participate in a region inside and outside taking research task and important public research institutions as a core. Ministry of Education, Culture, Sports, Science and Technology had designated 12 implementation regions in April 2002 and it started to implement in July 2002, more 3 regions in February 2003. Ministry of Economy, Trade and Industry implemented the industrial cluster plan to take each bureau of economy and industry as a point to institute the production, study and office network facing enterprises and universities in worldwide market. With local authority's support, 19 industrial cluster projects have been implemented. About3800 small and medium-sized enterprises as well as 200 universities participated composing the cross-region network.

\subsubsection{Various region innovation policies}

The region innovation policy mainly concentrates on the aspects below: a. The encouragement system, including all the correlation policies promoting regional innovation in Ministry of Internal Affairs and Communications, Ministry of Education, Culture, Sports, Science and Technology, Ministry of Economy, Trade and Industry, Ministry of Agriculture, Forestry and Fisheries and Ministry of environment; $b$. The improvement and operation of research achievements trading market, such as establishment of applying market to commercialize the research achievements in Hokkaido and other cities; c. the improvement of the research facilities to promote the regional science innovation; d. Strengthens $R \& D$ and technical support of the public experimental study organizations, including the support from Japanese Ministries to R\&D centers in state administration at different levels; e. Interaction and communication among regions including regional science innovation conference, research and communication among legal persons of each financial group in entire Japanese Region, as well as industrial technology advancement conference and so on.

\subsection{Korea: Establish the multi-layer city innovation system}

From 1995 Korea started to strengthen the research and the policy system establishment of the regional innovation system. Because the regional scope is small, the culture and system are with the strong homogeneity and the policy conduction function is effective. Therefore R\&D in many regions is dynamic and flexible well impelling innovation campaign. The construction and implementation of regional innovation system is easier than the national innovation 
system, and can provide a good foundation for the construction of high effective national innovation system.

Korean regional innovation system is divided into three kinds: Developed, developing and less-developed regional innovation system. In the developed regional innovation system, the distribution in both relative and absolute quantity of each innovation main body is reasonable. In the developing region innovation system, there are some flaws inside, but also it improves in the near future, especially, the quantity of public research facilities in this region is small. In less-developed regional innovation system, there is some big problem in its construction.

\section{Establishment of the Yangtze River Delta CARIS}

The Yangtze River Delta economic region with Shanghai as core, now has became the biggest foreign capital inflowing region and also the most conditional area in China that can takes part in the global division of labor. In north, the regions such as Beijing, Tianjin, Tangshan and economical belt at Gulf of Bo Hai also lead the development of the northwest areas and peripheral regions through its incomparably political center superiority and the abundantly economic potentiality.

Insert Figure 1 Here

Through the research of the Yangtze River Delta RIS, we discovered that the Yangtze River Delta CARIS is a developing model that is a core impetus and supplementary coexisting model and meanwhile a circle proliferation model. Display as follows: (1) Shanghai as the Yangtze River Delta center plays a good demonstration role in driving the development of Jiang and Zhe provinces, including: as a center of economy and resources, taking the lead of making policy and system, research and development, shipping, finance and trade centers and so on; (2) absorption and radiation of Shanghai to peripheral regions: it Includes absorption to talents and the fund resources from Jiang and Zhe provinces to Shanghai taking FDI as an example to reflect Shanghai radiation degree to the peripheral regions (3) supplementary function of Jiang and Zhe provinces to Shanghai: it reflects from aspects manifesting as industrial structure, resources and infrastructure construction and so on.

\subsection{The core role of Shanghai}

Shanghai is most developed city in Chinese economy, and its regional gross product, value-added of secondary and tertiary industry, total investment in the fixed assets, total volume of the retail sales of social consumer goods, total volume of imports and exports, the total volume of exports, the actually utilized foreign capital, etc as the main economic indicators are all in the first level in Chinese cities.

Insert Table 1 Here

As a center manifested in four aspects like economy, trade, finance, shipping, Shanghai, as the internationalization metropolis and the core of the Yangtze River Delta, has attracted the multitudinous innovation resources by the absolute superiority. At present, only Pudong block in Shanghai has already gathered 7 big state-level essential factors market for instance, negotiable securities, futures, shipping, technology, property right, talented persons and commodities and so on. There are more than 340 Chinese and foreign financial organ, more than 60 multinational corporation headquarters and more than hundred domestic big enterprise group headquarters, moreover, also some more than 100 multinational corporations research and develop centers and the domestic enterprise technological innovation centers and more than 4000 organizations in many kinds of professional service and so on, so that these become a core carrier for Shanghai to construct the international center with economy, trade, finance and shipping.

\subsection{Absorption and radiation of Shanghai to peripheral regions}

In the Yangtze River Delta CARIS, revolving Shanghai as a core, there also has formed some convergency and diffusion concretely represent in absorption and radiation of Shanghai to peripheral regions. Revolving the growth pole, in this region, several economic potentiality layers have been formed (chart 1). Economy is proliferated by the spatial shape.

Foreign direct investment (FDI) reflects opening degree and influence of Shanghai to other cities in this region. From Table 2, in Figure 1 we may see that the nearer to Shanghai the city is, the more FDI he gets. Foreign direct investment in the first layer is obviously higher than it in the second and third layer. The degree of dependency of Jiang and Zhe provinces to Shanghai also reflected radiation and driving function of Shanghai to the peripheral cities.

Insert Figure 2 Here

Insert Table 2 Here

\subsection{Undertaking and supplementary between peripheral industry and Shanghai industry}

In the Yangtze River Delta, besides driving function of Shanghai to the peripheral region, among layers there are great complementarities in industry, for instance, industrial and infrastructure construction supplementary and so on.

With the economic development of Pudong block from 90s, Shanghai adjusted the development strategy to concentrate 
on developing the high-tech industry like aeronautice and astronautics technologies, telecommunications and information technologies, new material and micro electron etc, these lead to emergence of new industry and substitution of leading industries, with the upgrade of Shanghai industrial structure, Jiangsu Province as a role of technical supplementary carried on undertaking Shanghai's traditional manufacturing industry, the radiation and diffusion of Shanghai's new and high technology naturally form the complementary technology connection between urban cities of Jiang and Zhe provinces and a complete set of industries among the interurban. Therefore, with promoting Shanghai industrial structure upgrade, Jiangsu has carried on undertaking adjusting its industrial structure forming the development situation of supplementary industries. Such as $\mathrm{Su}$, Xi, Chang as well as Kunshan all have established the state-level high and new technology development zone one after another; Suzhou built the cooperation development industry zone between china and Singapore, Zhejiang has formed the massive economical industrial cluster, like Ningbo' oil and chemistry industry cluster, Shaoxing's textile industry, Ningbo's apparel industry and so on.

Insert Table 3, Table 4 Here

\subsection{Inter-regional cooperative innovation in the trinity of enterprises, campuses and research institutes}

An important aspect of construction of regional innovation system in the Yangtze River Delta is that inter-regional cooperative innovation in the trinity of enterprises, campuses and research institutes. Shanghai is the most intensive place in R\&D in this region. From a point view of patent cooperation inside the region (see table 5), cooperative patents between Jiangsu and Zhejiang enterprises and Universities of Shanghai are most, this can be explained by that Jiangsu and Zhejiang paid attention to use Shanghai's universities resources to carry on the innovation cooperation, research and development centers in Shanghai display the core role in cooperative and supplementary.

In 2003, inside the Yangtze River Delta the number of patent cooperation accounted to 76 and the aggregate number is 194. (see table 6 and table 7) The number of cooperation patents among Beijing, Tianjin and Hebei is only 30 just taking $15.7 \%$ of that (191) between the Yangtze River Delta and neighboring provinces. This sufficiently certificates the breadth of patent cooperation of the Yangtze River Delta.

Insert Table 5, Table 6, Table 7 Here

\subsection{Construction of integrated infrastructure}

In the construction of integrated infrastructure, the Yangtze River Delta CARIS also takes Shanghai as the center, Jiangsu and Zhejiang provinces as two wings, and mutual supplementary among them will form a perfect infrastructure system. Taking the construction of harbor for example, in the Yangtze River Delta the connection between Chinese backland and overseas is always realized through the Shanghai international shipping center and the combination ports "Shanghai - - Ningbo - - Zhoushan" and so on, and most transportations are contributed as the result of harbor cooperation. So it is known that Shanghai as international shipping center that could not play the role of international shipping center function only depending on own conditions without Jiangsu and Zhejiang provinces.

\section{Evaluation and Suggestion}

\subsection{Evaluation}

\subsubsection{Evaluation of the recent RIP of the city of Shanghai}

I Constantly promote and perfect motivation policy for innovation and development of Shanghai.

II Promote innovation cluster to strengthen the competitiveness and superiority.

III Actively implement the support plan to encourage innovation of the small and medium-sized enterprises (SMEs).

\subsubsection{Evaluation of regional innovation and corporation}

I The reserve of regional innovation is not enough

Although the Yangtze River Delta in China is the most dynamic region with the greatest economic power and also is the more centralized area with scientific research institutions and universities, the economic power for R\&D in Jiangsu and Zhejiang except Shanghai is obviously low.

Insert Table 8 Here

II The selfishness inclination of local government

III The imperfect system of the science and technology innovation service agencies

At present, there are not the science and technology innovation service agencies with high level and great scale in the Yangtze River Delta, the existing agencies is of small scale and few service items; The quantity of promotion centers in the Yangtze River Delta for productive forces amounts to less than tenth of national quantity. This quantity is not compatible with the huge quantity of small and medium-sized enterprises, and the perfect system of agencies has not been founded. 
IV Scattered layout of the science and technology resources, lack of linkage in region

There are plenty of problem in division of labor and joint development and cooperation for national projects in the Yangtze River Delta. We must rectify and standardize the order of the market economy and establish a social credit system compatible with a modern market economy. We must get rid of trade monopolies and regional blockades to allow free movement of goods and production factors on markets around the country.

\subsection{Suggestion}

4.2.1. Government should take active suggestion to promote the institution innovation and cooperation and co-prosperity among cities in the Yangtze River Delta

I Strengthen urban agglomeration's cooperation and impel integration process of the Yangtze River Delta

II Enhance study and communication among urban agglomeration governments and make the governments to clearly know their roles in regional innovation system

\subsubsection{Strengthen the internal and external linkage of enterprises in the Yangtze River Delta}

Enterprises in market all have desires for technology innovation and the key task is to build convenient channel for technology innovation.

I Promote the optimization of industry structure and raise the industry concentration ration

II Improve the financial radiation and leading role of Shanghai further

4.2.3. The scientific research institute and university are the guarantees of technology innovation in the Yangtze River Delta

I Further strengthen the relationship between enterprises with the scientific research institutes and promote the communication between enterprisers with researchers

II Taking information technology application as method, build the information platform of technology resources among the urban agglomeration in the Yangtze River Delta

\section{References}

Jianjun Cheng. (2005). Study on Same Structure and Position of Industry in Delta Area of Changjiang River, Zhejiang University.

Evaluation of Synthetic Competitiveness of urban agglomerations of the Yangtze River Delta. (2005).

Xiangpeng Hu, Wei Chen. (2006). the report of development and innovation in the Yangtze River Delta. economy institute of Shanghai Academy of social Sciences.

Lee, D.S. and B.Choi. (2003). "Regional Innovation System and Regional Economic Development," in J. Lim(Ed.) Innovation for Regional Economy, Busan, Busan Development Institution.

Lei Liu. (2008). Research on the Layer Structure of Shanghai City Region, 09, Shanghai University.

National industry statistical yearbook from 2000 to 2004.

Shanghai city. Zhejiang and Suzhou provinces statistical yearbooks.

Zhixiang She, Peiyuan Yao \& Tang Zhenfu. industrial structure and structural adjustment in the Yangtze River Delta, (Nanjing Institute of Geography and Limnology); the Chinese Academy of Sciences; Nanjing.

Xidong Tao. (2004). The Research of Administrative Division Economy and Its Conformity Mechanism of Trans-Province Metropolitan Circle--As Xuzhou Metropolitan Circle a Example, Jiangsu University.

Xiang Wang. (2006). An Empirical Study on Manufacture Agglomeration and Regional Economic Integration in the Yangtze River Delta.

Chunxia Zhang. Research on Industrial Orientation of Main Cities in Shanghai Metropolis, Shanghai University.

Haohan Zhang. (2007). innovation-oriented country strategy and the Yangtze River Delta regional innovation system----the Yangtze River Delta corporative innovation, Jiangsu academy of social science

Mingzhi Zhang. (2005). A study on the mechanism of cooperation and coordination of global economy and interest of the country, Journal of Nanjing politics college (6):59 62. 
Table 1. Chief indexes of many cities in the Yangtze River Delta in 2004

\begin{tabular}{|c|c|c|c|c|c|c|c|}
\hline City & $\begin{array}{l}\text { Regional } \\
\text { domestic } \\
\text { production } \\
(100 \text { million } \\
\text { Yuan) }\end{array}$ & $\begin{array}{l}\text { per capita } \\
\text { GDP } \\
\text { (Yuan) }\end{array}$ & $\begin{array}{l}\text { Investment } \\
\text { in fixed } \\
\text { assets } \\
\text { nationwide } \\
(100 \\
\text { million } \\
\text { Yuan) }\end{array}$ & $\begin{array}{l}\text { Total volume of the } \\
\text { retail sales of social } \\
\text { consumer goods } \\
\text { (100 million Yuan) }\end{array}$ & $\begin{array}{l}\text { Total volume } \\
\text { of } \\
\text { exports\&imp } \\
\text { orts } \quad(100 \\
\text { million } \\
\text { dollar })\end{array}$ & $\begin{array}{l}\text { Total volume of } \\
\text { Exports }(100 \\
\text { million dollar) }\end{array}$ & $\begin{array}{l}\text { Actually utilized } \\
\text { foreign investment } \\
\text { (100 million dollar) }\end{array}$ \\
\hline Shanghai & $\begin{array}{l}7450.27 \\
(25.89 \%) \\
\end{array}$ & $\begin{array}{l}55090 \\
---- \\
\end{array}$ & $\begin{array}{l}3084.66 \\
(22.62 \%) \\
\end{array}$ & $\begin{array}{l}2454.61 \\
(29.72 \%) \\
\end{array}$ & $\begin{array}{l}1600.26 \\
(39.88 \%) \\
\end{array}$ & $\begin{array}{l}735.2 \\
(35.30 \%) \\
\end{array}$ & $\begin{array}{l}65.41 \\
(21.93 \%) \\
\end{array}$ \\
\hline Nanjing & 1910 & 33050 & 1201.88 & 711.44 & 206.39 & 104.6 & 15.12 \\
\hline Zhenjiang & 781.16 & 29235 & 320.5 & 192.05 & 34.79 & 15.19 & 12.2 \\
\hline Wuxi & 2350 & 52825 & 1114.13 & 579.21 & 218.46 & 110.22 & 19.48 \\
\hline Suzhou & 3450 & 57992 & 1554.80 & 625.10 & 1032.01 & 507.74 & 95 \\
\hline Hangzhou & 2515 & 38858 & 1205.18 & 704.34 & 244.96 & 151.75 & 14.1 \\
\hline Ningbo & 2158.04 & 39045 & 1095.7 & 595.63 & 261.13 & 166.90 & 21.03 \\
\hline $\begin{array}{l}\text { The Yangtze } \\
\text { River Delta }\end{array}$ & 28775.42 & 35040 & 13637.93 & 8258.59 & 4012.56 & 2082.96 & 298.245 \\
\hline
\end{tabular}

Table 2. Diffusion effect of Shanghai to periphery economic layer- - - foreign direct investment (FDI) comparison (unit: Ten thousand US dollars)

\begin{tabular}{|c|c|c|c|c|c|c|c|}
\hline \multicolumn{2}{|c|}{ economic layer } & 1998 & 1999 & 2000 & 2001 & 2002 & 2003 \\
\hline \multirow{5}{*}{$\begin{array}{l}\text { The core } \\
\text { layer }\end{array}$} & Suzhou & 285626 & 285626 & 288338 & 302183 & 481398 & 680511 \\
\hline & Wuxi & 100061 & 100061 & 108240 & 135746 & 174019 & 270057 \\
\hline & Hangzhou & 38425 & 42025 & 43093 & 50324 & 52186 & 100850 \\
\hline & Ningbo & 50329 & 52035 & 62186 & 87446 & 110502 & 172727 \\
\hline & Average & 119110 & 120437 & 125964 & 144425 & 205027 & 306537 \\
\hline \multirow{6}{*}{$\begin{array}{l}\text { The } \\
\text { second } \\
\text { outer } \\
\text { layer }\end{array}$} & Nanjing & 87247 & 87247 & 81277 & 90205 & 150162 & 220871 \\
\hline & Jiaxing & 12128 & 12300 & 15318 & 27067 & 44435 & 79682 \\
\hline & Shaoxing & 11593 & 7789 & 10474 & 15777 & 38167 & 74271 \\
\hline & Changzhou & 62569 & 62569 & 55977 & 62036 & 56120 & 85522 \\
\hline & Zhenjiang & 50840 & 50840 & 28925 & 32637 & 50095 & 80552 \\
\hline & Average & 68697 & 68236 & 63587 & 74429 & 108801 & 169487 \\
\hline \multirow{4}{*}{$\begin{array}{l}\text { The third } \\
\text { outer } \\
\text { layer }\end{array}$} & Yangzhou & 8129 & 8129 & 6654 & 9968 & 25580 & 48097 \\
\hline & Nantong & 30705 & 30705 & 14292 & 17523 & 23848 & 73092 \\
\hline & Zhoushan & 658 & 869 & 1055 & 1097 & 493 & 1704 \\
\hline & Average & 13164 & 13234 & 7333 & 9529 & 16640 & 40964 \\
\hline
\end{tabular}

Table 3. The top ten industries of Shanghai Manufacturing Sector

\begin{tabular}{|l|l|l|l|}
\hline 2002 & $\begin{array}{l}\text { Percentage of } \\
\text { production value }\end{array}$ & 2003 & $\begin{array}{l}\text { Percentage of } \\
\text { production } \\
\text { value }\end{array}$ \\
\hline $\begin{array}{l}\text { Electronics and telecommunications } \\
\text { industry }\end{array}$ & 12.58 & $\begin{array}{l}\text { Electronics and telecommunications } \\
\text { industry }\end{array}$ & 18.70 \\
\hline Transportation facilities & 12.17 & Transportation facilities & 15.31 \\
\hline Black metal smelting and rolling & 9.44 & Black metal smelting and rolling & 7.72 \\
\hline Electronic devices & 6.88 & Machinery manufacturing industry & 6.69 \\
\hline Chemical materials and chemicals & 6.68 & Electronic devices & 5.82 \\
\hline Machinery manufacturing industry & 5.08 & Chemical materials and chemicals & 5.54 \\
\hline Metal products & 4.23 & Petroleum processing & 5.04 \\
\hline Chemical fibre industry & 3.78 & Metal products & 3.49 \\
\hline Textile & 3.68 & Textile & 2.70 \\
\hline Apparel and other fiber industry & 3.27 & Professional equipment & 2.46 \\
\hline
\end{tabular}


Table 4. The top ten industries in Suzhou Province

\begin{tabular}{|l|l|l|l|}
\hline 2002 & & 2003 & \\
\hline Textile & 11.10 & Electronics and telecommunications industry & 14.39 \\
\hline $\begin{array}{l}\text { Electronics and telecommunications } \\
\text { industry }\end{array}$ & 10.23 & Textile & 10.14 \\
\hline Chemical materials and chemicals & 9.81 & Chemical materials and chemicals & 9.21 \\
\hline Machinery manufacturing industry & 6.85 & Black metal smelting and rolling & 6.85 \\
\hline Electronic devices & 6.69 & Machinery manufacturing industry & 6.55 \\
\hline Transportation facilities & 5.40 & Electronic devices & 6.19 \\
\hline Black metal smelting and rolling & 5.40 & Transportation facilities & 5.42 \\
\hline Apparel and other fiber industry & 4.07 & Metal products & 4.22 \\
\hline Metal products & 3.88 & Professional equipment & 2.95 \\
\hline Nonmetallic minerals products & 3.56 & $\begin{array}{l}\text { Electric power and stream, hot water product } \\
\text { and supply industry }\end{array}$ & 2.88 \\
\hline Source: national industry statistical yearbooks from 2000 to 2004. & \\
\hline
\end{tabular}

Table 5. The number of corporation patent between Shanghai and other regions

\begin{tabular}{|l|l|l|l|l|l|l|l|l|l|l|}
\hline Place & \multicolumn{2}{|l|}{ Shanghai province } & \multicolumn{2}{l|}{ Jiangsu province } & \multicolumn{2}{l|}{ Zhiang province } \\
\hline Mechanism type & Enterprise & $\begin{array}{l}\text { Univ } \\
\text { ersit } \\
\mathrm{y}\end{array}$ & $\begin{array}{l}\text { Acade } \\
\text { my }\end{array}$ & $\begin{array}{l}\text { Enterpr } \\
\text { ise }\end{array}$ & $\begin{array}{l}\text { Univer } \\
\text { sity }\end{array}$ & $\begin{array}{l}\text { Acade } \\
\text { my }\end{array}$ & Enterprise & University & $\begin{array}{l}\text { Acade } \\
\text { my }\end{array}$ \\
\hline $\begin{array}{l}\text { Shanghai } \\
\text { Enterprise }\end{array}$ & 106 & 19 & 18 & 8 & 0 & 1 & 3 & 0 & 0 \\
\hline $\begin{array}{l}\text { Shanghai } \\
\text { university }\end{array}$ & 109 & 3 & 9 & 11 & 1 & 0 & 6 & 3 & 0 \\
\hline Shanghai academy & 28 & 13 & 12 & 0 & 1 & 0 & 4 & 0 & 0 \\
\hline
\end{tabular}

Table 6. Three kinds of patents and corporation application in 2003(unit: piece)

\begin{tabular}{|l|l|l|l|l|l|l|l|}
\hline & Person & Enterprise & University & Academy & Others & $\begin{array}{l}\text { Corporation } \\
\text { (proportion) }\end{array}$ & Total \\
\hline Beijing & 1772 & 1543 & 857 & 772 & 18 & $306(5.8 \%)$ & 5233 \\
\hline Tianjing & 362 & 816 & 303 & 53 & 0 & $23(1.5 \%)$ & 1555 \\
\hline Hebei & 410 & 88 & 17 & 1 & 0 & $14(2.7 \%)$ & 525 \\
\hline Shanghai & 821 & 1215 & 967 & 403 & 4 & $269(7.4 \%)$ & 3632 \\
\hline Jiangsu & 868 & 586 & 403 & 65 & 37 & $51(2.5 \%)$ & 2009 \\
\hline Zhejiang & 984 & 394 & 371 & 32 & 4 & $72(3.9 \%)$ & 1844 \\
\hline
\end{tabular}

Table7. Corporation application of three kinds of patents in the Yangtze River Delta and the Beijing-Tianjin-Tanggu(BTT) (unit: piece)

\begin{tabular}{|c|c|c|c|c|c|c|c|}
\hline Region & Total & In province & $\begin{array}{l}\text { With } \\
\text { neighboring } \\
\text { provinces }\end{array}$ & $\begin{array}{l}\text { With Other } \\
\text { provinces }\end{array}$ & $\begin{array}{l}\text { Total of } \\
\text { neighboring and } \\
\text { other provinces }\end{array}$ & $\begin{array}{l}\text { Total of } \\
\text { Neighboring } \\
\text { provinces }\end{array}$ & $\begin{array}{l}\text { The Beijing-Tianjin-Tanggu } \\
\text { (BTT) }\end{array}$ \\
\hline Shanghai & 432 & 317 & 38 & 77 & 115 & \multirow[t]{3}{*}{90} & \multirow[t]{3}{*}{76} \\
\hline Jiangsu & 112 & 77 & 24 & 11 & 35 & & \\
\hline Zhejiang & 106 & 62 & 28 & 16 & 44 & & \\
\hline Beijing & 426 & 269 & 21 & 136 & 157 & \multirow[t]{3}{*}{30} & \multirow[t]{3}{*}{30} \\
\hline Tianjing & 34 & 15 & 3 & 16 & 19 & & \\
\hline Hebei & 20 & 5 & 6 & 9 & 15 & & \\
\hline
\end{tabular}


Table 8. Scientific \& Technological Activities by Region in the Yangtze River Delta

\begin{tabular}{|l|l|l|l|l|}
\hline Index & \multicolumn{2}{l|}{\begin{tabular}{l} 
2000 \\
\hline The proportion of R\&D expenditure in GDP(\%)
\end{tabular} 2002 } & 2003 \\
\hline National Average & 1.00 & 1.23 & 1.31 & 1.44 \\
\hline Shanghai & 1.69 & 1.89 & 2.06 & 2.29 \\
\hline Jiangsu & $/$ & 1.03 & 1.21 & 1.38 \\
\hline Zhejiang & 0.87 & 0.83 & 1.17 & 1.28 \\
\hline $\begin{array}{l}\text { the proportion of technological development expenditure of } \\
\text { large and medium-sized enterprises in the sales revenue(\%) }\end{array}$ & \multicolumn{5}{|l|}{} \\
\hline National Average & 1.65 & 1.73 & 1.52 & 1.49 \\
\hline Shanghai & 1.57 & 1.52 & 1.31 & 1.82 \\
\hline Jiangsu & $/$ & $/$ & 1.12 & 1.27 \\
\hline Zhejiang & 0.53 & $/$ & 0.66 & 0.63 \\
\hline
\end{tabular}

Source: china statistical yearbook, Shanghai statistical yearbook, Jiangsu statistical yearbook, Zhejiang statistical yearbook (several issues for all)

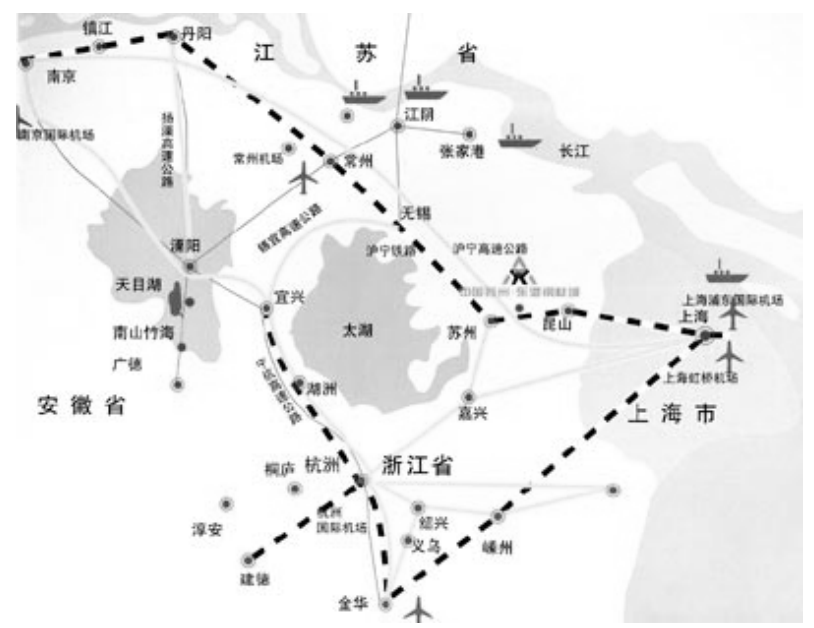

Figure 1. The Yangtze River Delta

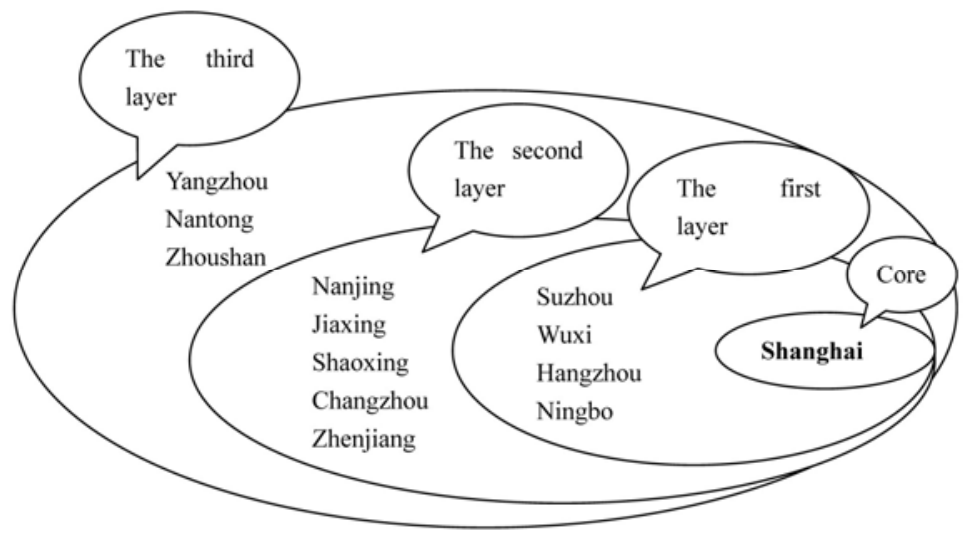

Figure2. The economic layer structure in the Yangtze River Delta

Description for the above figure 